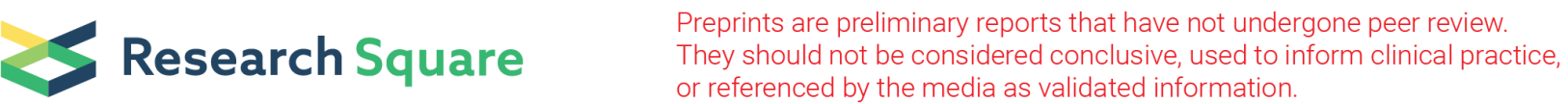

\section{The Cre/CysC Ratio can Predict Muscle Composition and is Associated with Glucose Disposal Ability and Macrovascular Disease in Patients with Type 2 Diabetes}

\section{Qing Yang}

Jining Medical University

Mei Zhang

Jining Medical University

\section{Peng Sun}

Jining Medical University

Yanying Li

Jining Medical University

Huichao Xu

Jining Medical University

Kejun Wang

Jining Medical University

Hongshan Shen

Jining Medical University

\section{Bo Ban}

Jining Medical University

Fupeng Liu ( $\square$ liufupengsdu@126.com )

Jining Medical University

Original investigation

Keywords: creatinine, cystatin C, muscle composition, sarcopenia, type 2 diabetes

Posted Date: June 7th, 2021

DOl: https://doi.org/10.21203/rs.3.rs-532475/v1

License: (c) (1) This work is licensed under a Creative Commons Attribution 4.0 International License.

Read Full License 


\section{Abstract}

Background: Since the ratio of creatinine to cystatin C (Cre/CysC) can reflect muscle volume, it has been proven to be a predictor of sarcopenia in patients with or without diabetes. Here, we investigated the predictive value of Cre/CysC in skeletal muscle composition and its correlations with glucose disposal ability and diabetic complications in patients with type 2 diabetes.

Methods: The skeletal muscle index (SMI) and mean skeletal muscle attenuation (MMA) values of 193 patients with type 2 diabetes were obtained through analyses of CT images at the lumbar 3 level.

Results: Serum Cre/CysC was significantly correlated with both the SMI $(r=0.375, P<0.001)$ and MMA ( $r$ $=0.378, \mathrm{P}<0.001)$. Multiple stepwise linear regression analysis demonstrated that $\mathrm{Cre} / \mathrm{CysC}$ was the only biochemical predictor of the SMI $[b=0.48,(95 \% \mathrm{Cl}, 0.02$ to 0.94$)$ and MMA $[b=0.57,(95 \% \mathrm{Cl}, 0.14$ to 1.01). In the diabetic complications analysis, $\mathrm{Cre} / \mathrm{CysC}$ was negatively correlated with cardiovascular disease $(r=-0.190, P=0.008)$ and lower extremity arterial disease $(r=-0.209, P=0.004)$. Moreover, in the $100 \mathrm{~g}$ steamed bun test, Cre/CysC was significantly correlated with glucose levels at $60 \mathrm{~min}(r=-0.162, P$ $=0.045), 120 \mathrm{~min}(r=-0.287, P<0.001)$ and $180 \min (r=-0.313, P<0.001)$.

Conclusions: $\mathrm{Cre} / \mathrm{CysC}$ is a valuable predictor of skeletal muscle composition in type 2 diabetes. Patients with higher levels of Cre/CysC may have a better ability to dispose of postprandial glucose and lower risk of macrovascular disease.

\section{Background}

Type 2 diabetes mellitus is a group of metabolic disorders characterized by hyperglycaemia due to impaired insulin secretion and increased insulin resistance [1]. In addition to common diabetic complications, the vasculopathy and accumulation of advanced glycation end-products can impair muscle mass and function, leading to sarcopenia [2]. A recent systematic review including 1,832 patients with type 2 diabetes and 4,694 euglycaemic subjects demonstrated that patients with type 2 diabetes have a higher risk of sarcopenia (OR: 1.55, [95\% Cl: 1.25-1.91]). Considering its heavy impact on quality of life and increased risk of fracture, disability and mortality, sarcopenia is emerging as a third category of diabetic complication [3, 4].

Sarcopenia is defined as the presence of both low muscle mass and reduced function (strength or performance) [5]. Several imaging modalities can be used to assess muscle mass and achieve the diagnosis of sarcopenia $[5,6]$. Among these methods, magnetic resonance (MR) and computed tomography (CT) are considered to be gold standards for the non-invasive assessment of muscle mass [7]. However, in addition to the high cost, the equipment is not immediately accessible in primary care, and radiological technicians are required to operate it.

The ratio of creatinine to cystatin C (Cre/CysC) was first reported in 2013 as a surrogate marker of muscle mass [8]. On this basis, $\mathrm{Cre} / \mathrm{CysC}$ has been proven to be an accurate and inexpensive predictor of 
sarcopenia in patients with chronic obstructive pulmonary disease, non-dialysis chronic kidney disease and diabetes [9-11]. However, unlike other diseases, type 2 diabetes patients mainly present reduced muscle performance and strength, which correlate with muscle density, but have no difference in muscle mass $[12,13]$. Therefore, we hypothesize that in addition to muscle mass, the Cre/Cys C ratio can predict muscle density in type 2 diabetes patients. Considering that skeletal muscle is the main consumer of glucose as well as the association between sarcopenia and diabetic complications, we also evaluated the correlation of $\mathrm{Cre} / \mathrm{Cys} \mathrm{C}$ with glucose disposal ability and diabetic complications.

Unlike other imaging modalities, CT can assess both muscle volume and density because increased fat infiltration in muscle results in lower CT attenuation [14]. Therefore, we performed this retrospective study to assess the predictive value of Cre/CysC in skeletal muscle composition, which was measured by CT scans in type 2 diabetes.

\section{Methods}

\section{Study patients}

Type 2 diabetes patients hospitalized in the Department of Endocrinology, Affiliated Hospital of Jining Medical University, from January 2017 to December 2020, who underwent CT scans including the centre plane of the third lumbar vertebra on axial images and had blood analysis of creatinine and cystatin $\mathrm{C}$ levels were included in this study. The exclusion criteria were as follows: (1) patients missing anthropometric measures such as height and weight; (2) patients with malignant tumours, abnormal thyroid function, or stage $V$ diabetic nephropathy; and (3) patients who were receiving haemodialysis or immunosuppressive drugs.

\section{Laboratory measurements and complications assessment}

All biochemical and immune indexes were measured at our hospital laboratory. The Cre/CysC ratio was calculated by dividing serum creatinine $(\mathrm{mg} / \mathrm{L})$ by serum cystatin $\mathrm{C}(\mathrm{mg} / \mathrm{L})$. Patients underwent a $100 \mathrm{~g}$ steamed bun test when they had good glucose control after intensive insulin therapy. Diabetic complications were assessed systematically according to the guidelines for the prevention and control of type 2 diabetes in China [15].

\section{Body composition measurements}

Two authors identified axial CT images at the L3 level in which the spinous process and the 2 transverse processes could be visualized. Image analysis included the skeletal muscle index (SMI), mean skeletal muscle attenuation (MMA) and fat mass index (FMI). Slice-0-Matic software (version 5.0, TomoVision, Montreal, Quebec, Canada) was used for image analysis by setting attenuation thresholds from - 29 to 150 Hounsfield units (HU) for skeletal muscle, -150 to $-30 \mathrm{HU}$ for visceral adipose tissue and - 190 to -30 HU for intramuscular/subcutaneous adipose tissue [16]. Each type of tissue found in each L3 CT image was then shaded with a different colour, corresponding to these thresholds. Data outputs for the area in $\mathrm{cm}^{2}$ of each tissue type in each CT image were collected and used to calculate the SMI and the FMI. Total 
adiposity, including visceral, subcutaneous and intramuscular adipose tissue, was used to calculate the fat mass using the equation fat mass in $\mathrm{kg}=0.042 \times$ (total adipose area at L3 in $\mathrm{cm}^{2}$ ) +11.2 [17]. FMI was calculated by normalizing the fat mass in $\mathrm{kg}$ by height in $\mathrm{m}^{2}$. The SMI was calculated by normalizing the $\mathrm{L} 3$ cross-sectional skeletal muscle area in $\mathrm{cm}^{2}$ by height in $\mathrm{m}^{2}$. The MMA was automatically calculated by the software.

\section{Statistical analysis}

Continuous variables are summarized using the median and interquartile range (IQR) if not normally distributed and the mean \pm standard deviation (SD) if normally distributed. Categorical variables are summarized as the frequency count and percent. These variables between the two groups were compared by independent samples t-test or the Mann-Whitney $\mathrm{U}$ test. Categorical variables were analysed by the chi-square test. Univariable correlations between variables were assessed by Pearson's correlation coefficient. Independent factors associated with the SMI and MMA were analysed by multiple stepwise linear regression. Statistical analysis was performed using SPSS software (version 26.0). A p value less than 0.05 was considered statistically significant.

\section{Results}

A total of 254 diabetic patients with axial CT images at the L3 level were searched in the hospital management system. After screening the discharge diagnosis, patient state and biochemical information, 193 type 2 diabetes patients were included in the present study (see Fig. 1). The SMI and MMA evaluated skeletal composition from different angles. As shown in Fig. 2, patient A had a similar SMI to patient B but a much higher MMA. In contrast, patient $C$ had a similar MMA to patient $D$ but a much higher SMI.

\section{Patients' characteristics}

The patients' characteristics are presented in Table 1. A total of 114 male patients and 79 female patients with a mean age of 55.45 years were enrolled in this study. Male patients had higher serum creatinine levels, Cre/CysC ratios, and SMI and MMA values than female patients. 
Table 1

Patients' characteristics included in this study

\begin{tabular}{|c|c|c|c|c|}
\hline Characteristics & Total $(n=193)$ & Male $(n=114)$ & Female $(n=79)$ & $\mathrm{p}$ value \\
\hline Age(years) & $55.45 \pm 11.73$ & $53.25 \pm 12.29$ & $58.62 \pm 10.13$ & 0.002 \\
\hline Duration(months) & $84(24,132)$ & $72(12,123)$ & $96(36,144)$ & 0.091 \\
\hline $\mathrm{BMI}\left(\mathrm{kg} / \mathrm{m}^{2}\right)$ & $26.08 \pm 3.42$ & $26.66 \pm 3.07$ & $25.25 \pm 3.73$ & 0.005 \\
\hline WHR & $0.94 \pm 0.06$ & $0.95 \pm 0.05$ & $0.92 \pm 0.06$ & 0.001 \\
\hline Creatinine $(\mathrm{mg} / \mathrm{L})$ & $6.76 \pm 1.91$ & $7.53 \pm 1.78$ & $5.65 \pm 1.50$ & $<0.01$ \\
\hline Cystatin C (mg/L) & $0.98 \pm 0.33$ & $1.01 \pm 0.34$ & $0.93 \pm 0.31$ & 0.129 \\
\hline Cre/CysC & $7.26 \pm 2.06$ & $7.86 \pm 2.07$ & $6.38 \pm 1.71$ & $<0.01$ \\
\hline Albumin $(\mathrm{g} / \mathrm{L})$ & $42.53 \pm 4.62$ & $42.97 \pm 4.41$ & $41.90 \pm 4.87$ & 0.115 \\
\hline BUN (mmol/L) & $5.47 \pm 1.52$ & $5.60 \pm 1.55$ & $5.30 \pm 1.47$ & 0.177 \\
\hline TG (mmol/L) & $1.45(0.98,2.12)$ & $1.52(1.16,2.27)$ & $1.23(0.83,1.84)$ & 0.004 \\
\hline $\mathrm{TCH}(\mathrm{mmol} / \mathrm{L})$ & $4.54 \pm 1.15$ & $4.36 \pm 1.14$ & $4.80 \pm 1.13$ & 0.009 \\
\hline HDL (mmol/L) & $1.11 \pm 0.29$ & $1.03 \pm 0.25$ & $1.22 \pm 0.31$ & $<0.001$ \\
\hline LDL (mmol/L) & $2.63 \pm 0.86$ & $2.47 \pm 0.82$ & $2.86 \pm 0.87$ & 0.002 \\
\hline HbA1c (\%) & $8.65 \pm 1.90$ & $8.51 \pm 1.89$ & $8.85 \pm 1.92$ & 0.231 \\
\hline $\mathrm{FBG}(\mathrm{mmol} / \mathrm{L})$ & $7.24 \pm 2.28$ & $6.91 \pm 1.95$ & $7.72 \pm 2.63$ & 0.021 \\
\hline $\mathrm{FCP}(\mathrm{ng} / \mathrm{ml})$ & $2.22 \pm 0.94$ & $2.36 \pm 0.89$ & $2.02 \pm 0.97$ & 0.02 \\
\hline HOMA2 \%B & $79.29 \pm 44.05$ & $87.89 \pm 44.76$ & $66.96 \pm 40.20$ & 0.002 \\
\hline HOMA2 \%S & $66.35 \pm 34.08$ & $62.20 \pm 29.53$ & $72.30 \pm 39.17$ & 0.059 \\
\hline HOMA2 IR & $1.83 \pm 0.82$ & $1.89 \pm 0.77$ & $1.74 \pm 0.88$ & 0.248 \\
\hline Hypertension (\%) & $89(46.11)$ & $54(47.37)$ & $35(44.30)$ & 0.675 \\
\hline CV disease (\%) & $59(30.57)$ & $29(25.44)$ & $30(37.97)$ & 0.063 \\
\hline DPN (\%) & 147(76.17) & $87(76.32)$ & $60(75.95)$ & 0.953 \\
\hline LEAD (\%) & $109(56.48)$ & $63(55.26)$ & $46(58.23)$ & 0.683 \\
\hline DN (\%) & $82(42.49)$ & $47(41.23)$ & $35(44.30)$ & 0.671 \\
\hline \multicolumn{5}{|c|}{$\begin{array}{l}\text { Abbreviations: Cre/CysC, creatinine to cystatin C ratio; BUN, blood urea nitrogen; TG, triglyceride; TCH } \\
\text { total cholesterol; HDL, high-density lipoproteins; LDL, low density lipoproteins; FBG, fasting blood } \\
\text { glucose; FCP, fasting C-peptide; CV, cardiovascular; DPN, diabetic peripheral neuropathy; LEAD, lower } \\
\text { extremity arterial disease; DN, diabetic nephropathy; DR, diabetic retinopathy; SMI, skeletal muscle } \\
\text { index; MMA, mean skeletal muscle attenuation; FMI, fat mass index. }\end{array}$} \\
\hline
\end{tabular}




\begin{tabular}{|lllll|}
\hline Characteristics & Total $(\mathbf{n}=\mathbf{1 9 3})$ & Male $(\mathbf{n}=114)$ & Female $(\mathbf{n}=\mathbf{7 9})$ & p value \\
\hline $\mathrm{DR}(\%)$ & $44(22.80)$ & $23(20.18)$ & $21(26.58)$ & 0.297 \\
$\mathrm{SMI}\left(\mathrm{cm}^{2} / \mathrm{m}^{2}\right)$ & $47.80 \pm 8.71$ & $52.59 \pm 6.81$ & $40.87 \pm 6.11$ & $<0.001$ \\
$\mathrm{MMA}\left(\mathrm{cm}^{2} / \mathrm{m}^{2}\right)$ & $37.11 \pm 6.82$ & $39.14 \pm 5.95$ & $34.17 \pm 6.96$ & $<0.001$ \\
\hline $\mathrm{FMI}(\mathrm{HU})$ & $8.63 \pm 1.82$ & $8.36 \pm 1.72$ & $9.01 \pm 1.89$ & $\mathbf{0 . 0 1 4}$ \\
\hline $\begin{array}{l}\text { Abbreviations: Cre/CysC, creatinine to cystatin C ratio; BUN, blood urea nitrogen; TG, triglyceride; TCH, } \\
\text { total cholesterol; HDL, high-density lipoproteins; LDL, low density lipoproteins; FBG, fasting blood } \\
\text { glucose; FCP, fasting C-peptide; CV, cardiovascular; DPN, diabetic peripheral neuropathy; LEAD, lower } \\
\text { extremity arterial disease; DN, diabetic nephropathy; DR, diabetic retinopathy; SMl, skeletal muscle } \\
\text { index; MMA, mean skeletal muscle attenuation; FMl, fat mass index. }\end{array}$ & \\
\hline
\end{tabular}

\section{Correlations of the SMI and MMA with clinical factors}

The correlations between the SMI and MMA and clinical factors are shown in Table 2. Both the SMI and MMA were significantly associated with the Cre/CysC ratio (SMI: $r=0.375, P<0.001$; MMA: $r=0.378, P<$ $0.001)$. Serum creatinine was associated with the SMI $(r=0.382, P<0.001)$ but was not associated with MMA $(r=0.132, P=0.067)$. Serum cystatin was not associated with the SMI $(r=-0.046, p=0.524)$ but was associated with MMA $(r=-0.234, p=0.010)$. The scatter diagram of serum creatinine and cystatin $C$ and their ratio with the SMI and MMA are shown in Fig. 3. Notably, BMI and waist-hip ratio (WHR) were positively correlated with the SMI (BMI: $r=0.505, P<0.001$; WHR: $r=0.286, P<0.001)$ but negatively correlated with MMA (BMI: $r=-0.178, P=0.013$; WHR: $r=-0.149, P=0.045)$. Furthermore, disease duration and FMI were significantly associated with MMA (duration: $r=-0.234, P=0.001 ; F M I: r=-0.481, P<0.001$ ) but not with the SMI (duration: $r=-0.134, P=0.063 ; F M I: r=0.101, P=0.164$ ). Multiple stepwise linear regression analyses of variables related to the SMI and MMA are listed in Table 3. After adjusting for confounding factors, Cre/CysC was the only biochemical predictor of the $S M I[\beta=0.48,(95 \% \mathrm{Cl}, 0.02$ to 0.94)] and MMA [ $\beta=0.57,(95 \% \mathrm{Cl}, 0.14$ to 1.01$)]$. 
Table 2

Correlation between skeletal composition and clinical factors

\begin{tabular}{|c|c|c|c|c|}
\hline \multirow[t]{2}{*}{ Variants } & \multicolumn{2}{|l|}{ SMI } & \multicolumn{2}{|l|}{ MMA } \\
\hline & $\mathbf{r}$ & $\mathrm{p}$ value & $\mathbf{r}$ & $p$ value \\
\hline Male & $0.664^{\star \star \star}$ & $<0.001$ & $0.359^{\star \star \star}$ & $<0.001$ \\
\hline Age(years) & $-0.288^{\star \star \star}$ & $<0.001$ & $-0.481^{\star \star \star}$ & $<0.001$ \\
\hline Duration (months) & -0.134 & 0.063 & $-0.234^{\star \star}$ & 0.001 \\
\hline $\mathrm{BMI}\left(\mathrm{kg} / \mathrm{m}^{2}\right)$ & $0.505^{\star \star \star}$ & $<0.001$ & $-0.178^{*}$ & 0.013 \\
\hline WHR & $0.286^{\star \star \star}$ & $<0.001$ & $-0.149^{\star}$ & 0.045 \\
\hline Creatinine (mg/L) & $0.382^{\star \star \star}$ & $<0.001$ & 0.132 & 0.067 \\
\hline Cystatin C (mg/L) & -0.046 & 0.524 & $-0.234^{*}$ & 0.010 \\
\hline Cre/CysC & $0.375^{\star \star \star}$ & $<0.001$ & $0.378^{\star \star \star}$ & $<0.001$ \\
\hline Albumin $(\mathrm{g} / \mathrm{L})$ & $0.250^{\star \star \star}$ & $<0.001$ & $0.163^{*}$ & 0.024 \\
\hline BUN (mmol/L) & 0.095 & 0.190 & 0.051 & 0.483 \\
\hline $\mathrm{TG}(\mathrm{mmol} / \mathrm{L})$ & 0.144 & 0.046 & $0.171^{*}$ & 0.018 \\
\hline $\mathrm{TCH}(\mathrm{mmol} / \mathrm{L})$ & -0.099 & 0.172 & -0.067 & 0.357 \\
\hline HDL (mmol/L) & $-0.248^{\star \star}$ & 0.001 & $-0.165^{*}$ & 0.022 \\
\hline LDL (mmol/L) & -0.139 & 0.055 & $-0.156^{*}$ & 0.031 \\
\hline HbA1c (\%) & 0.061 & 0.403 & 0.016 & 0.826 \\
\hline FBG (mmol/L) & $-0.172^{\star}$ & 0.022 & -0.083 & 0.273 \\
\hline $\mathrm{FCP}(\mathrm{ng} / \mathrm{ml})$ & $0.185^{*}$ & 0.015 & 0.047 & 0.534 \\
\hline HOMA2 \%B & $0.284^{\star \star \star}$ & $<0.001$ & 0.082 & 0.292 \\
\hline HOMA2 \%S & $-0.223^{\star \star}$ & 0.004 & -0.016 & 0.839 \\
\hline HOMA2 IR & 0.126 & 0.104 & 0.016 & 0.840 \\
\hline
\end{tabular}

Abbreviations: $\mathrm{Cre} / \mathrm{CysC}$, creatinine to cystatin $\mathrm{C}$ ratio; $\mathrm{BUN}$, blood urea nitrogen; $\mathrm{TG}$, triglyceride; $\mathrm{TCH}$, total cholesterol; HDL, high-density lipoproteins; LDL, low density lipoproteins; FBG, fasting blood glucose; FCP, fasting C-peptide; CV, cardiovascular; DPN, diabetic peripheral neuropathy; LEAD, lower extremity arterial disease; DN, diabetic nephropathy; DR, diabetic retinopathy; SMI, skeletal muscle index; MMA, mean skeletal muscle attenuation; FMI, fat mass index. 


\begin{tabular}{|c|c|c|c|c|}
\hline \multirow[t]{2}{*}{ Variants } & \multicolumn{2}{|l|}{ SMI } & \multicolumn{2}{|l|}{ MMA } \\
\hline & $\mathbf{r}$ & p value & $\mathbf{r}$ & $\mathrm{p}$ value \\
\hline Hypertension (\%) & 0.073 & 0.311 & $-0.141^{*}$ & 0.050 \\
\hline CV disease (\%) & -0.140 & 0.052 & $-0.242^{\star \star}$ & 0.001 \\
\hline DPN (\%) & 0.037 & 0.605 & -0.102 & 0.158 \\
\hline $\operatorname{LEAD}(\%)$ & -0.037 & 0.611 & -0.090 & 0.212 \\
\hline DN (\%) & 0.062 & 0.389 & $-0.165^{\star}$ & 0.022 \\
\hline DR (\%) & -0.054 & 0.389 & -0.040 & 0.578 \\
\hline $\operatorname{SMI}\left(\mathrm{cm}^{2} / \mathrm{m}^{2}\right)$ & 1.000 & - & $0.409^{\star \star \star}$ & $<0.001$ \\
\hline $\operatorname{MMA}\left(\mathrm{cm}^{2} / \mathrm{m}^{2}\right)$ & $0.409^{\star \star \star}$ & $<0.001$ & 1.000 & - \\
\hline $\mathrm{FMI}(\mathrm{HU})$ & 0.101 & 0.164 & $-0.481^{\star \star \star}$ & $<0.001$ \\
\hline \multicolumn{5}{|c|}{$\begin{array}{l}\text { Abbreviations: Cre/CysC, creatinine to cystatin C ratio; BUN, blood urea nitrogen; TG, triglyceride; TCH, } \\
\text { total cholesterol; HDL, high-density lipoproteins; LDL, low density lipoproteins; FBG, fasting blood } \\
\text { glucose; FCP, fasting C-peptide; CV, cardiovascular; DPN, diabetic peripheral neuropathy; LEAD, lower } \\
\text { extremity arterial disease; DN, diabetic nephropathy; DR, diabetic retinopathy; SMI, skeletal muscle } \\
\text { index; MMA, mean skeletal muscle attenuation; FMI, fat mass index. }\end{array}$} \\
\hline
\end{tabular}


Table 3

Multiple stepwise linear regression analysis of factors associated with the SMI and MMA

\begin{tabular}{|c|c|c|}
\hline Variables & Beta (95\% Cl) & $p$ value \\
\hline \multicolumn{3}{|l|}{ SMI } \\
\hline Male & $9.06(7.18,10.95)^{* \star \star}$ & $<0.001$ \\
\hline BMI & $1.00(0.75,1.26)^{* * \star}$ & $<0.001$ \\
\hline Age & $-0.10(-0.18,-0.02)$ * & 0.012 \\
\hline Cre/CysC & $0.48(0.02,0.94)$ * & 0.042 \\
\hline \multicolumn{3}{|l|}{ MMA } \\
\hline Male & $3.68(1.89,5.47))^{\star \star \star}$ & $<0.001$ \\
\hline BMI & $-0.48(-0.72,-0.24)^{\star * *}$ & $<0.001$ \\
\hline Age & $-0.21(-0.28,-0.13){ }^{\star \star \star}$ & $<0.001$ \\
\hline Cre/CysC & $0.57(0.14,1.01)^{*}$ & 0.011 \\
\hline \multicolumn{3}{|c|}{$\begin{array}{l}\text { Adopted factors: gender, age, BMI, WHR, Cre/CysC, creatinine, albumin, high-density lipoproteins, } \\
\text { HOMA2 \%B, HOMA2 \%S, fasting blood glucose and fasting c-peptide for SMl; gender, age, duration, } \\
\text { BMI, WHR, Cre/CysC, cystatin C, albumin, triglyceride, high-density lipoproteins, low density } \\
\text { lipoproteins, hypertension, cardiovascular disease and diabetic nephropathy for MMA. } \mathrm{R}^{2}=0.788 \text { for } \\
\text { SMl and 0.612 for MMA. Cre/CysC, creatinine to cystatin C ratio; SMI, skeletal muscle index; MMA, } \\
\text { mean skeletal muscle attenuation. }\end{array}$} \\
\hline
\end{tabular}


Table 4

Correlation of Cre/CysC with diabetic complications and the $100 \mathrm{~g}$ steamed bun test

\begin{tabular}{|llllll|}
\hline Complications & CV disease & DPN & LEAD & DN & DR \\
\hline$r$ & $-0.190^{* *}$ & -0.078 & $-0.209^{* \star}$ & -0.034 & -0.111 \\
\hline p value & $\mathbf{0 . 0 0 8}$ & 0.283 & $\mathbf{0 . 0 0 4}$ & 0.639 & 0.123 \\
\hline Glucose & $0 \mathrm{~min}$ & $30 \mathrm{~min}$ & $60 \mathrm{~min}$ & $120 \mathrm{~min}$ & $180 \mathrm{~min}$ \\
\hline $\mathrm{r}$ & -0.121 & -0.146 & $-0.162^{*}$ & $-0.287^{\star \star \star}$ & $-0.313^{\star \star \star}$ \\
\hline p value & 0.109 & 0.071 & $\mathbf{0 . 0 4 5}$ & $<0.001$ & $<0.001$ \\
\hline C peptide & $0 \mathrm{~min}$ & $30 \mathrm{~min}$ & $60 \mathrm{~min}$ & $120 \mathrm{~min}$ & $180 \mathrm{~min}$ \\
\hline$r$ & -0.006 & -0.004 & 0.046 & 0.106 & 0.086 \\
\hline p value & 0.942 & 0.959 & 0.575 & 0.191 & 0.287 \\
\hline
\end{tabular}

Abbreviations: CV, cardiovascular; DPN, diabetic peripheral neuropathy; LEAD, lower extremity arterial disease; DN, diabetic nephropathy; DR, diabetic retinopathy.

\section{Correlation of $\mathrm{Cre} / \mathrm{Cys} \mathrm{C}$ with diabetic complications and the $100 \mathrm{~g}$ steamed bun test}

Considering the predictive value of $\mathrm{Cre} / \mathrm{CysC}$ in muscle composition, its correlation with diabetic complications and the $100 \mathrm{~g}$ steamed bun test was further evaluated. In the diabetic complications analysis, Cre/CysC was significantly correlated with cardiovascular disease $(r=-0.190, P=0.008)$ and lower extremity arterial disease $(r=-0.209, P=0.004)$. Moreover, in the $100 \mathrm{~g}$ steamed bun test, $\mathrm{Cre} / \mathrm{CysC}$ was significantly correlated with glucose levels at $60 \mathrm{~min}(r=-0.162, P=0.045), 120 \mathrm{~min}(r=-0.287, P<$ $0.001)$ and $180 \mathrm{~min}(r=-0.313, P<0.001)$.

\section{Discussion}

Creatinine originates from skeletal muscle and is affected by renal function, while cystatin $\mathrm{C}$, another serum marker of renal function, is a cysteine proteinase inhibitor that functions as a housekeeping gene excreted by all nucleated cells [18-20]. Therefore, the ratio of Cre/CysC corrected for renal function can reflect the total muscle volume in the body. However, muscle function, another key diagnostic element of sarcopenia, is correlated with muscle density rather than muscle size. Moreover, patients with diabetes mainly present reduced muscle performance and strength. To date, no study has evaluated the predictive value of Cre/CysC for muscle density.

This study first reported that Cre/CysC is an independent predictor of both the SMI and MMA. The predictive function of $\mathrm{Cre} / \mathrm{CysC}$ in MMA may be one of the main principles of Cre/CysC predicting sarcopenia in patients with type 2 diabetes. This result is also consistent with a previous study showing 
that $\mathrm{Cre} / \mathrm{CysC}$ predicts muscle strength in patients with non-dialysis-requiring chronic kidney disease [11]. Moreover, both the SMI and MMA are independent predictors of the outcome in critically ill patients [21]. Therefore, Cre/CysC has also been proven to be a predictor of outcome in patients treated in the ICU [22, 23]. Based on the above evidence, $\mathrm{Cre} / \mathrm{CysC}$ could be regarded as a more comprehensive indicator of skeletal muscle composition and thereby predict sarcopenia, muscle strength and the outcome of patients with critical illness.

In addition to $\mathrm{Cre} / \mathrm{CysC}$, anthropometric characteristics, including sex, age and $\mathrm{BMI}$, are independent predictors of the SMI and MMA. It is easy to understand that SMI and MMA values are higher in male patients than in female patients and decrease gradually with increasing age. Since overnutrition and lack of physical exercise are major inducers of type 2 diabetes, obesity, dyslipidaemia and abnormal fat distribution are common comorbidities in these patients. This study indicated that BMI and WHR are positively correlated with the SMI but negatively correlated with MMA. Furthermore, diabetes duration and the FMI were significantly negatively associated with MMA but not with the SMI. Therefore, the decrease in muscle density might be a major pathogenic mechanism of sarcopenia in type 2 diabetes.

Considering that skeletal muscle is the main consumer of glucose and the main target of insulin activity [24], this study further evaluated the correlation between Cre/CysC and the $100 \mathrm{~g}$ steamed bun test. Our research showed that Cre/CysC is negatively correlated with postprandial blood glucose but has no correlation with c-peptide release. Interestingly, there was no correlation between Cre/CysC and HOMA2 indexes. These results indicate that patients with high levels of Cre/CysC may have better postprandial glucose disposal ability, even though they showed no differences in pancreatic function and insulin sensitivity. The present study did show a correlation between Cre/CysC and $\mathrm{HbA} 1 \mathrm{c}$, which is consistent with previous epidemiological studies showing that $\mathrm{HbA} 1 \mathrm{c}$ is not associated with sarcopenia in type 2 diabetes individuals [3]. However, a relationship between glucose control and sarcopenia cannot be completely excluded. Our study indicates that postprandial glucose disposal ability may decrease in type 2 diabetes patients with sarcopenia.

There are some indications that low muscle mass and reduced function could be associated with diabetic complications [3]. The present study has shown that Cre/CysC is negatively correlated with macrovascular diseases, including cardiovascular disease and lower extremity arterial disease, and this might be attributed to the impact of cystatin $\mathrm{C}$. This study also showed that cystatin $\mathrm{C}$ is positively correlated with cardiovascular disease and lower extremity arterial disease $(r=0.211, P=0.003$ and $r=$ $0.164, P=0.023$, respectively; data not shown). This is consistent with previous studies showing that cystatin $C$, rather than creatinine, is independently associated with heart and peripheral arterial disease [25-29].

In adults, the normal range of cystatin $\mathrm{C}$ is 0.51 to $0.98 \mathrm{mg} / \mathrm{L}$ independent of sex and age [30]. The normal range of creatinine for males is 0.6 to $1.2 \mathrm{mg} / \mathrm{dl}$, and for females, it is 0.5 to $1.1 \mathrm{mg} / \mathrm{dl}$ [31]. Therefore, the ratio of Cre/CysC should be near 10. Some studies provided Cre/CysC values near 1 or 100 because they calculated the $\mathrm{Cre} / \mathrm{CysC}$ ratio with different formulas: $\mathrm{Cre} / \mathrm{CysC}$ ratio $=[($ serum creatinine 
$\{\mathrm{mg} / \mathrm{dl}\} /$ serum cystatin $\mathrm{C}\{\mathrm{mg} / \mathrm{l}\}) \times 100]$ or (serum creatinine $\{\mathrm{mg} / \mathrm{dl}\} /$ serum cystatin $\mathrm{C}\{\mathrm{mg} / \mathrm{l}\})[9-11,32-$ 34]. With more attention given to the ratio of $\mathrm{Cre} / \mathrm{CysC}$, a recognized and accepted formula should be proposed by an official institute.

Our study has some limitations. First, this is a single-centre study with a small sample population, and the findings in the present study should be further validated by further large-sample studies. Second, we did not assess muscle function (e.g., handgrip strength and gait speed), which has recently been advised by the European Working Group on Sarcopenia in Older People (EWGSOP) as one of the referred criteria for severe sarcopenia [14]. Third, as this was a retrospective study, we did not repeatedly assess the muscle composition and Cre/CysC; therefore, the predictive value of changes in Cre/CysC for muscle composition over time is unknown. Finally, further large sample studies are needed to better understand the prognostic value of Cre/CysC for diabetic complications.

\section{Conclusions}

In conclusion, the present study indicated that the ratio of Cre/CysC is a valuable predictor of skeletal muscle composition in type 2 diabetes. Additionally, patients with higher levels of Cre/CysC may have a better ability to dispose of postprandial glucose and lower risk of macrovascular disease.

\section{Abbreviations}

Cre/CysC, creatinine to cystatin C; SMI, skeletal muscle index; MMA, mean skeletal muscle attenuation; MR, magnetic resonance; CT, computed tomography; FMI, fat mass index; HU, Hounsfield units; IQR, interquartile range; SD, standard deviation; WHR, waist-hip ratio; EWGSOP, European Working Group on Sarcopenia in Older People.

\section{Declarations}

\section{Ethics approval and consent to participate}

Not applicable

\section{Consent for publication}

Not applicable

\section{Availability of data and materials}

The datasets generated and analysed during the current study are not publicly available but are available from the corresponding author on reasonable request 


\section{Competing interests}

The authors declare that they have no competing interests

\section{Founding}

The present study was supported by the Doctoral foundation of Affiliated Hospital of Jining Medical University (2020-BS-008).

\section{Authors' contributions}

Concept and design: QY, MZ, PS, YL, HX, KW, HS, BB, FL. Acquisition, analysis, or interpretation of data: QY, FL, MZ, PS. Drafting of the manuscript: QY, FL. Critical revision of the manuscript for important intellectual content: QY, MZ, PS, YL, HX, KW, HS, BB, FL. Statistical analysis: QY, FL. Obtained funding: FL. Supervision: MZ, PS, YL, BB. All authors read and approved the final manuscript.

\section{Acknowledgements}

Not applicable

\section{References}

1. American Diabetes Association: 2. Classification and Diagnosis of Diabetes: Standards of Medical Care in Diabetes-2019. Diabetes care 2019, 42(Suppl 1):S13-s28.

2. Chiu CY, Yang RS, Sheu ML, Chan DC, Yang TH, Tsai KS, Chiang CK, Liu SH: Advanced glycation endproducts induce skeletal muscle atrophy and dysfunction in diabetic mice via a RAGE-mediated, AMPK-down-regulated, Akt pathway. The Journal of pathology 2016, 238(3):470-482.

3. Izzo A, Massimino E, Riccardi G, Della Pepa G: A Narrative Review on Sarcopenia in Type 2 Diabetes Mellitus: Prevalence and Associated Factors. Nutrients 2021, 13(1).

4. Mesinovic J, Zengin A, De Courten B, Ebeling PR, Scott D: Sarcopenia and type 2 diabetes mellitus: a bidirectional relationship. Diabetes, metabolic syndrome and obesity : targets and therapy 2019, 12:1057-1072.

5. Cruz-Jentoft AJ, Bahat G, Bauer J, Boirie Y, Bruyère O, Cederholm T, Cooper C, Landi F, Rolland Y, Sayer AA et al: Sarcopenia: revised European consensus on definition and diagnosis. Age and ageing 2019, 48(1):16-31.

6. Albano D, Messina C, Vitale J, Sconfienza LM: Imaging of sarcopenia: old evidence and new insights. European radiology 2020, 30(4):2199-2208. 
7. Beaudart C, McCloskey E, Bruyère O, Cesari M, Rolland Y, Rizzoli R, Araujo de Carvalho I, Amuthavalli Thiyagarajan J, Bautmans I, Bertière MC et al: Sarcopenia in daily practice: assessment and management. BMC geriatrics 2016, 16(1):170.

8. Tetsuka S, Morita M, Ikeguchi K, Nakano IJN, Neuroscience C: Creatinine/cystatin C ratio as a surrogate marker of residual muscle mass in amyotrophic lateral sclerosis. 2013.

9. Osaka T, Hamaguchi M, Hashimoto Y, Ushigome E, Tanaka M, Yamazaki M, Fukui M: Decreased the creatinine to cystatin $\mathbf{C}$ ratio is a surrogate marker of sarcopenia in patients with type 2 diabetes. Diabetes research and clinical practice 2018, 139:52-58.

10. Hirai K, Tanaka A, Homma T, Goto Y, Akimoto K, Uno T, Yoshitaka U, Miyata Y, Inoue H, Ohta S et al: Serum creatinine/cystatin $\mathrm{C}$ ratio as a surrogate marker for sarcopenia in patients with chronic obstructive pulmonary disease. Clinical nutrition (Edinburgh, Scotland) 2021, 40(3):1274-1280.

11. Lin YL, Chen SY, Lai YH, Wang CH, Kuo CH, Liou HH, Hsu BG: Serum creatinine to cystatin C ratio predicts skeletal muscle mass and strength in patients with non-dialysis chronic kidney disease. Clinical nutrition (Edinburgh, Scotland) 2020, 39(8):2435-2441.

12. Anagnostis P, Gkekas NK, Achilla C, Pananastasiou G, Taouxidou P, Mitsiou M, Kenanidis E, Potoupnis M, Tsiridis E, Goulis DG: Type 2 Diabetes Mellitus is Associated with Increased Risk of Sarcopenia: A Systematic Review and Meta-analysis. Calcified tissue international 2020, 107(5):453463.

13. Wang L, Yin L, Zhao Y, Su Y, Sun W, Chen S, Liu Y, Yang M, Yu A, Guglielmi G et al: Muscle Density, but Not Size, Correlates Well With Muscle Strength and Physical Performance. Journal of the American Medical Directors Association 2020.

14. Lenchik L, Boutin RD: Sarcopenia: Beyond Muscle Atrophy and into the New Frontiers of Opportunistic Imaging, Precision Medicine, and Machine Learning. Seminars in musculoskeletal radiology 2018, 22(3):307-322.

15. Chinese medical association diabetes association: Guidlines for the prevention and control of type 2 diabetes in China.Chin J Endocrinol Metab 2015, 30(2):893-942.

16. Albersheim J, Sathianathen NJ, Zabell J, Renier J, Bailey T, Hanna P, Konety BR, Weight CJ: Skeletal Muscle and Fat Mass Indexes Predict Discharge Disposition after Radical Cystectomy. The Journal of urology 2019, 202(6):1143-1149.

17. Mourtzakis M, Prado CM, Lieffers JR, Reiman T, McCargar LJ, Baracos VE: A practical and precise approach to quantification of body composition in cancer patients using computed tomography images acquired during routine care. Applied physiology, nutrition, and metabolism = Physiologie appliquee, nutrition et metabolisme 2008, 33(5):997-1006.

18. Abrahamson M, Olafsson I, Palsdottir A, Ulvsbäck M, Lundwall A, Jensson O, Grubb A: Structure and expression of the human cystatin C gene. The Biochemical journal 1990, 268(2):287-294.

19. Levey AS, Perrone RD, Madias NE: Serum creatinine and renal function. Annual review of medicine 1988, 39:465-490. 
20. Viollet L, Gailey S, Thornton DJ, Friedman NR, Flanigan KM, Mahan JD, Mendell JR: Utility of cystatin C to monitor renal function in Duchenne muscular dystrophy. Muscle \& nerve 2009, 40(3):438-442.

21. Loosen SH, Schulze-Hagen M, Püngel T, Bündgens L, Wirtz T, Kather JN, Vucur M, Paffenholz P, Demir M, Bruners P et al: Skeletal Muscle Composition Predicts Outcome in Critically III Patients. Critical care explorations 2020, 2(8):e0171.

22. Kashani KB, Frazee EN, Kukrálová L, Sarvottam K, Herasevich V, Young PM, Kashyap R, Lieske JC: Evaluating Muscle Mass by Using Markers of Kidney Function: Development of the Sarcopenia Index. Critical care medicine 2017, 45(1):e23-e29.

23. Barreto EF, Poyant JO, Coville HH, Dierkhising RA, Kennedy CC, Gajic O, Nystrom EM, Takahashi N, Moynagh MR, Kashani KB: Validation of the sarcopenia index to assess muscle mass in the critically ill: A novel application of kidney function markers. Clinical nutrition (Edinburgh, Scotland) 2019, 38(3):1362-1367.

24. DeFronzo RA: Lilly lecture 1987. The triumvirate: beta-cell, muscle, liver. A collusion responsible for NIDDM. Diabetes 1988, 37(6):667-687.

25. Huh JH, Choi E, Lim JS, Lee MY, Chung CH, Shin JY: Serum cystatin C levels are associated with asymptomatic peripheral arterial disease in type 2 diabetes mellitus patients without overt nephropathy. Diabetes research and clinical practice 2015, 108(2):258-264.

26. Kaneko R, Sawada S, Tokita A, Honkura R, Tamura N, Kodama S, Izumi T, Takahashi K, Uno K, Imai J et al: Serum cystatin $\mathrm{C}$ level is associated with carotid arterial wall elasticity in subjects with type 2 diabetes mellitus: A potential marker of early-stage atherosclerosis. Diabetes research and clinical practice $2018,139: 43-51$.

27. Koenig W, Twardella D, Brenner H, Rothenbacher D: Plasma concentrations of cystatin C in patients with coronary heart disease and risk for secondary cardiovascular events: more than simply a marker of glomerular filtration rate. Clinical chemistry 2005, 51(2):321-327.

28. Lee SH, Park SA, Ko SH, Yim HW, Ahn YB, Yoon KH, Cha BY, Son HY, Kwon HS: Insulin resistance and inflammation may have an additional role in the link between cystatin $\mathrm{C}$ and cardiovascular disease in type 2 diabetes mellitus patients. Metabolism: clinical and experimental 2010, 59(2):241-246.

29. Maahs DM, Snell-Bergeon JK, Hokanson JE, Kinney GL, Berl T, Rewers M, Ogden LG: Relationship between cystatin $\mathrm{C}$ and coronary artery atherosclerosis progression differs by type 1 diabetes. Diabetes technology \& therapeutics 2010, 12(1):25-33.

30. Finney H, Newman DJ, Price CP: Adult reference ranges for serum cystatin $\mathrm{C}$, creatinine and predicted creatinine clearance. Annals of clinical biochemistry 2000, 37 (Pt 1):49-59.

31. Hosten AO: BUN and Creatinine. In: Clinical Methods: The History, Physical, and Laboratory Examinations. Edited by Walker HK, Hall WD, Hurst JW. Boston: Butterworths. Copyright (C) 1990, Butterworth Publishers, a division of Reed Publishing.; 1990.

32. Komorita Y, Iwase M, Fujii H, Ide H, Ohkuma T, Jodai-Kitamura T, Sumi A, Yoshinari M, Nakamura U, Kitazono $\mathrm{T}$ : The serum creatinine to cystatin $\mathrm{C}$ ratio predicts bone fracture in patients with type 2 diabetes: The Fukuoka Diabetes Registry. Diabetes research and clinical practice 2018, 146:202-210. 
33. Amado CA, García-Unzueta MT, Lavin BA, Guerra AR, Agüero J, Ramos L, Muñoz P: The Ratio Serum Creatinine/Serum Cystatin C (a Surrogate Marker of Muscle Mass) as a Predictor of Hospitalization in Chronic Obstructive Pulmonary Disease Outpatients. Respiration; international review of thoracic diseases 2019, 97(4):302-309.

34. Yanishi M, Kinoshita H, Tsukaguchi H, Kimura Y, Koito Y, Sugi M, Matsuda T: The creatinine/cystatin $\mathrm{C}$ ratio provides effective evaluation of muscle mass in kidney transplant recipients. International urology and nephrology 2019, 51(1):79-83.

\section{Figures}

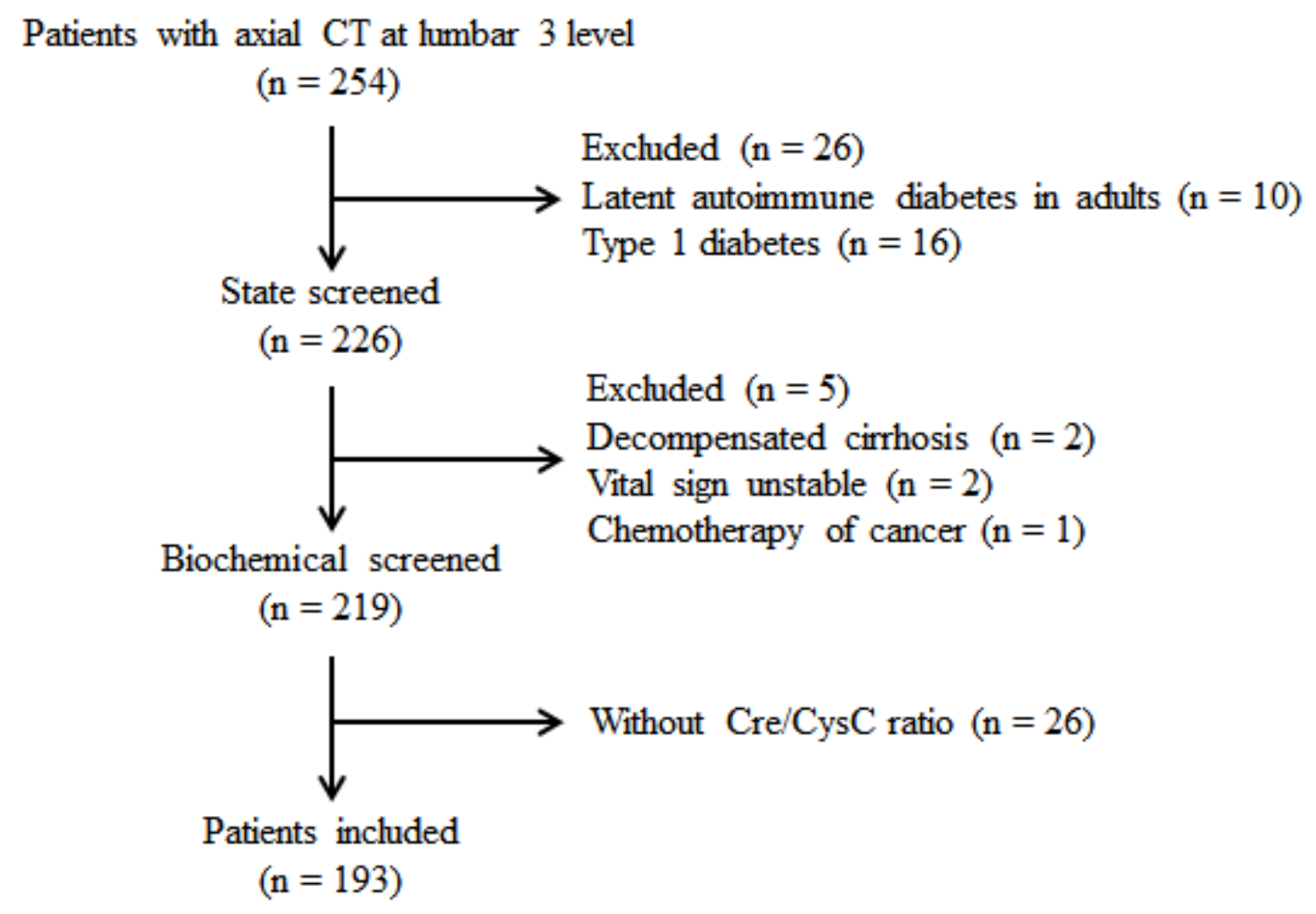

\section{Figure 1}

The screening process of patients enrolled in this study. 


\section{A}

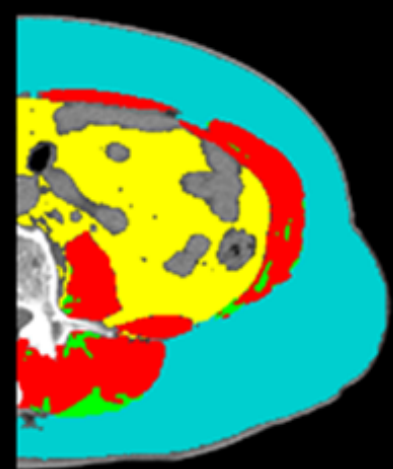

60 years old Female SMI: $33.96 \mathrm{~cm}^{2} / \mathrm{m}^{2}$ FMI: $63.72 \mathrm{~kg} / \mathrm{m}^{2}$

C

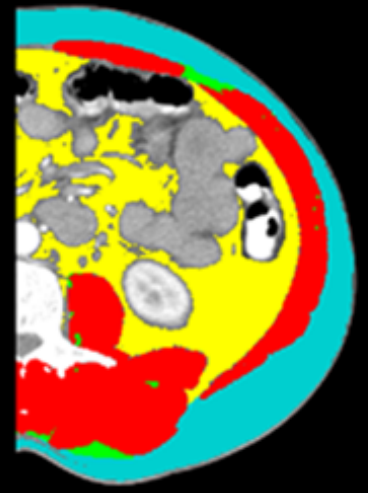

49 years old Male SMI: $55.72 \mathrm{~cm}^{2} / \mathrm{m}^{2}$ FMI: $52.75 \mathrm{~kg} / \mathrm{m}^{2}$

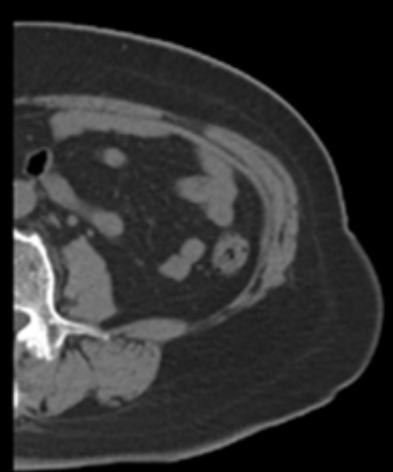

MMA: $35.34 \mathrm{HU}$

BMI: $24.39 \mathrm{~kg} / \mathrm{m}^{2}$

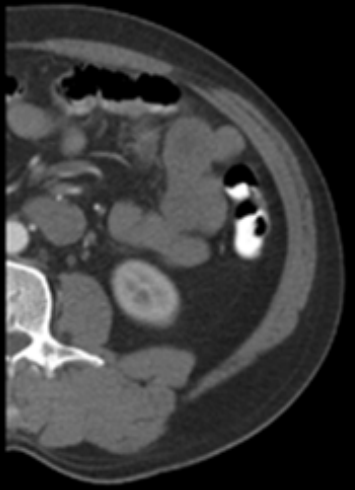

MMA: $39.47 \mathrm{HU}$

BMI: $26.00 \mathrm{~kg} / \mathrm{m}^{2}$
B
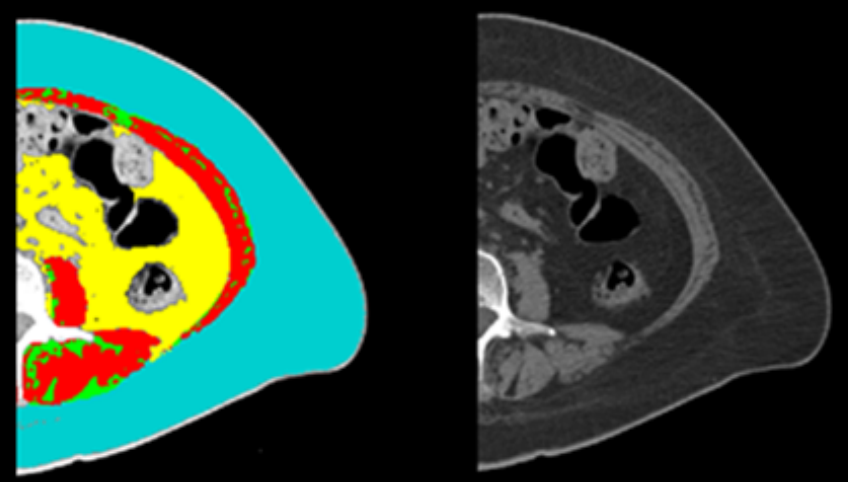

64 years old Female SMI: $34.22 \mathrm{~cm}^{2} / \mathrm{m}^{2}$ FMI: $87.43 \mathrm{~kg} / \mathrm{m}^{2}$

MMA: $16.36 \mathrm{HU}$ BMI: $26.95 \mathrm{~kg} / \mathrm{m}^{2}$

D
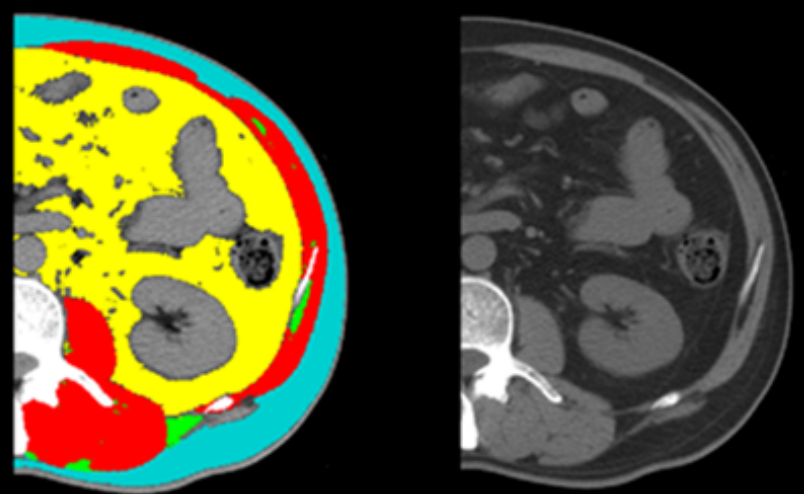

49 years old Male SMI: $34.45 \mathrm{~cm}^{2} / \mathrm{m}^{2}$ MMA: $39.50 \mathrm{HU}$ FMI: $44.99 \mathrm{~kg} / \mathrm{m}^{2} \quad$ BMI: $23.08 \mathrm{~kg} / \mathrm{m}^{2}$

Figure 2

CT image analysis at the lumbar 3 level using Slice-O-Matic software. Red, muscle; Blue, subcutaneous adipose tissue; Yellow, visceral adipose tissue; Green, intermuscular adipose tissue; Grey, unprocessed CT image; SMI, skeletal muscle index; MMA, mean skeletal muscle attenuation; FMI, fat mass index; BMI, body mass index. 

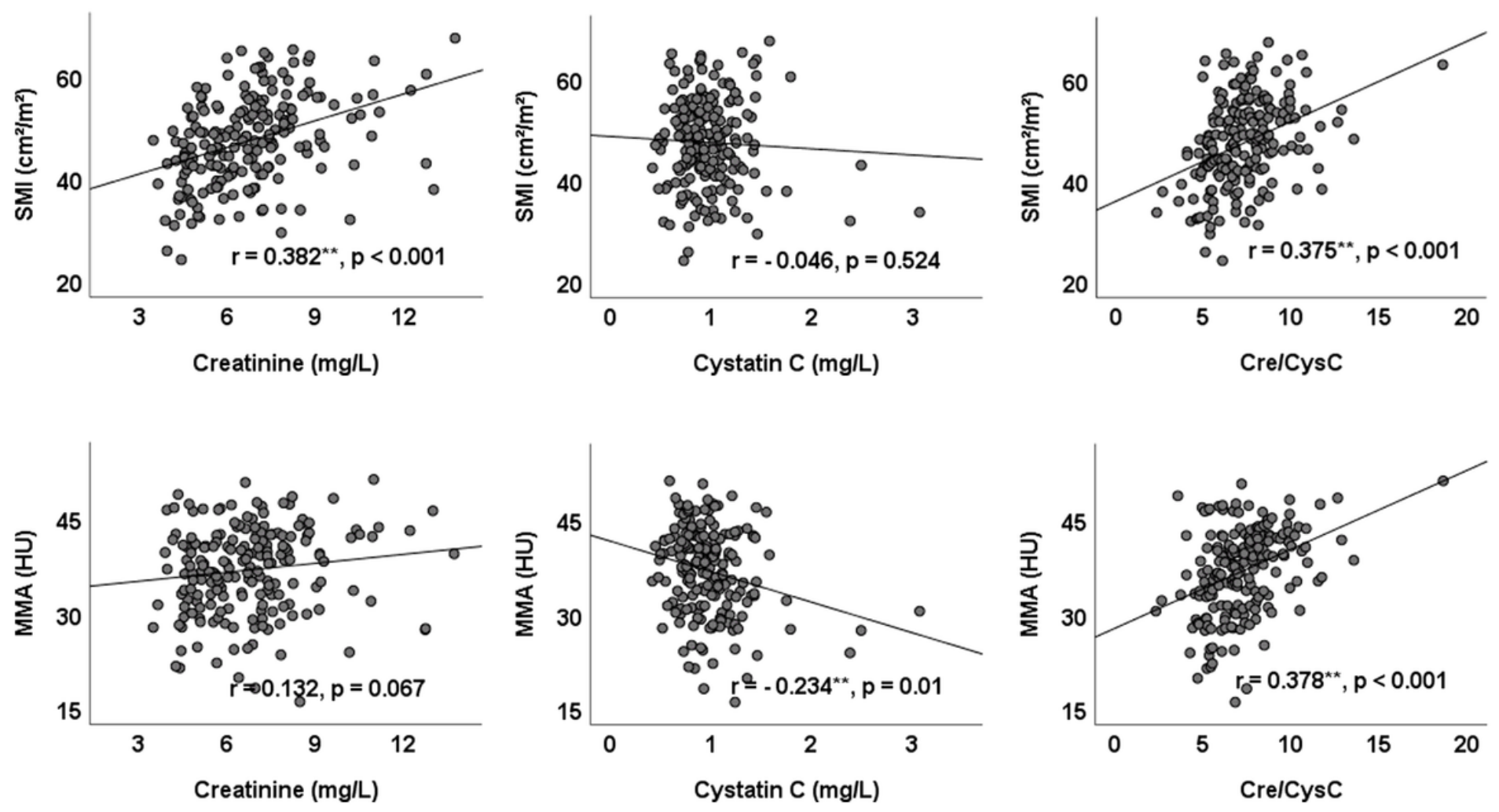

Figure 3

Scatter diagram of creatinine and cystatin $\mathrm{C}$ and their ratio Cre/CysC with the SMI and MMA. SMI, skeletal muscle index; MMA, mean skeletal muscle attenuation. 